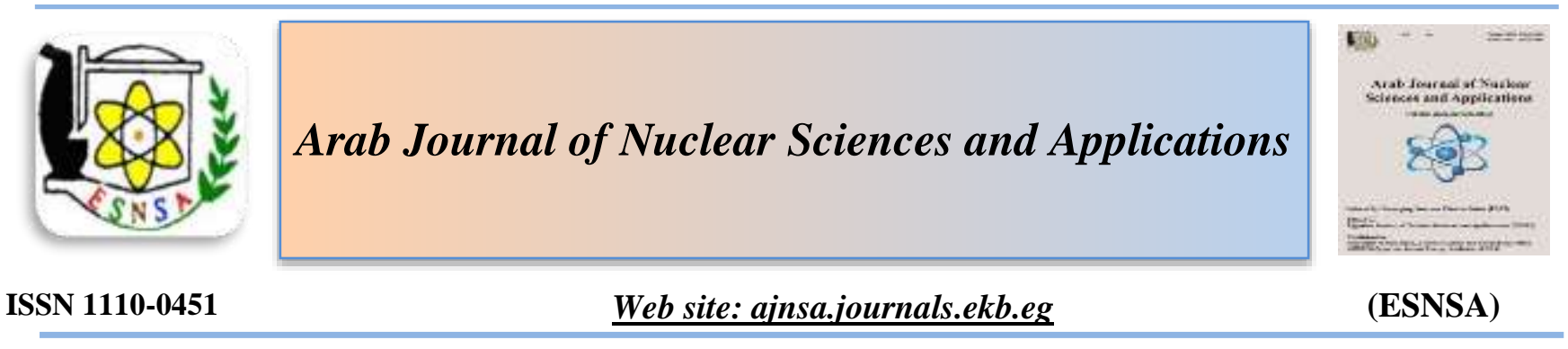

\title{
Impact of $\gamma$-Irradiation Processing on the Efficiency of Antioxidant Activity of Pomegranate (Punica Granatum L.) By-Products and Guava (Psidium Guajava L.) Leaves
}

\author{
M. Diaa El-Din H. Farag (1), Sawsan A. Abd-Elhalim ${ }^{(2)}$, Hayat M. Sharada ${ }^{(2)}$, Hania F.G. El-Niely ${ }^{(1)}$ \\ and Shimaa R. Shaban ${ }^{(2)}$ \\ (1) Food Irradiation Research Department, Industrial Irradiation Division, National Center for Radiation \\ Research and Technology, Atomic Energy Authority, Cairo, Egypt \\ ${ }^{(2)}$ Chemistry Department, Helwan University, Helwan, Egypt
}

Received 07 Oct 2019 Accepted 15 Jun 2020
Three fruit by-products namely red peel of pomegranate (exocarp or pericarp), white pulp (mesocarp or albedo) and guava leaves were investigated for their contents of total phenols, total tannins and Diphenyl picryl hydrazylfree radical (DPPH) scavenging activity. The effect of different irradiation doses on these parameters was also studied. The results showed reasonable contents of phenols, tannins and high DPPH radical scavenging activities. Guava leaves indicated the highest radical scavenging activity. The effect of gamma irradiation showed a higher antioxidant activity in case of red peel at $30 \mathrm{kGy}$. Lower antioxidant activity was recorded for the white a pulp at all doses which was parallel to its tannin contents. Almost no significant change was noticed in the antioxidant activity of guava leaves, being extremely high in all cases. Generally, all irradiated fruit by-products studied indicated high antioxidant activities after irradiation. Even in case of the white pulp, which showed the lowest antioxidant activity after irradiation, it retained more than $70 \%$ of its natural antioxidant activity. The study recommends using these by-products as food preservatives, supplementary feeds for animals and in preparation of pharmacological products. Guava leaves stabilized by irradiation seem to be the best for food preservation being the highest in antioxidant activity.

Keywords: Radiation effects, Antioxidant activity, Fruit by-products

\section{Introduction}

Food irradiation is the single most studied food processing technology for toxicological preservation [1]. The Codex Alimenatrius International Food Standards permits three types of ionizing radiation to be used on food. This includes gamma rays from radioactive cobalt-60 or Cesium137, high energy electrons, and X-rays [2]. Gamma irradiation is an effective method to reduce the microbial load and to extend the shelf life of products without any detrimental effect on food quality [3].It is significantly less expensive than Xrays $[2,4]$.

Fruit and vegetable wastes and by-products, which are formed in great amounts during industrial processing, represent a serious problem, as they exert an influence on environment and to be managed or utilized. On the other hand they are rich in bioactive compounds that may be suitable for other purposes [5].

Pomegranate peel comprises about $50 \%$ of the total fruit weight and is an important source of minerals

Corresponding author: shymaashaaban900@yahoo.com

DOI: 10.21608/ajnsa.2020.17902.1282

(C) Scientific Information, Documentation and Publishing Office (SIDPO)-EAEA 
and polysaccharides and high levels of bioactive compounds [6]. Pomegranate peel, being free from phytic acid, plays an important role in the bakery products as food additives. The peel is low in fat and is a good source of dietary fiber, protein and phytochemicals. It may have therapeutic activity due to its high content of dietary fiber as in hypercholesterolemia, diabetes and cancer [7]. The application of pomegranate peel as a natural fertilizer was studied by Mercy et al.,2014[8]. Saleh et al., 2017[9] investigated the effect of the addition of pomegranate peel powder on the hygienic quality of beef sausage. The antibacterial effect of pomegranate peel extract was further studied by Jaisinghani et al.,2018 [10]. Medical applications for pomegranate peel extract included its effect on atherosclerotic plaque formation [11] and on wound healing[12].

Application of guava leaves have been verified by several investigators over the last decade against many disorders, demonstrating its potential in the treatment of the most common worldwide diseases. This has been related to individual compounds such as quercetin, catechin, gallic acid and others [13]. The potency of guava leaves as a functional immunostimulatory ingredient was studied by Laily et al.,2015 [14] and David et al.,2017 [15]. Elsayed et al.,2013[16] indicated that supplementation of broiler diets with dried guava leaves significantly improved performance and health of the birds. Phytochemical, biochemical and antimicrobial activities of guava leaf extract were investigated by Anbuselvi and Rebecca 2017(17). Areview on the nutritional, Medicinal and pharmacological properties of Guava fruit, leaf and other parts of guava (pisidium guajava Linn) was reported by (18). Guave leaves were used to prepare gelatin beads with marine-fish gelatin for various applications such as medicine, and the food pharmaceutical industries (19). Giri et al.,2015(20) and Fawoel et al.,2016 (21) suggested guava leaves as supplementary feed for fish. Gobi et al., 2016(22) reported that guava leaf powder, mixed with a commercial diet, strengthened the immunological response of tilapia fish and recommended the leaves as feed complement in aquaculture. Guava leaves were found to be a potential treatment for scurvy (23). The impact of chitosan and guava leaf extract as preservatives to extend the shelf-life of fruits was indicated by Islam et al., 2018(24). The removal of synthetic dyes from waste water by using guava leaf powder, as an adsorbent, was shown by Raja
2012(25) and Ojedokum et al.,2017(26). The main objectives of this study were to investigate the effects of various gamma irradiation dose levels on total phenolic content, total tannin content and free radical scavenging activity of some fruit byproducts.

\section{MATERIALS AND METHODS}

The studied byproduct included pomegranate red peel (pericarp or exocarp), pomegranate white pulp (albedo or mesocarp) and guava leaves. Pomegranate fruits were purchased from the local market, Helwan, Egypt. They were manually peeled and the red peel was separated from the white pulp. Fresh leaves of psidium guava were collected from open grassland in Helwan. All plant by-products were rinsed with distilled water then were left in shade at room temperature for two weeks after drying in an oven for 24 hours at $65^{\circ} \mathrm{C}$.

\section{Irradiation process}

Dried pomegranate peel, pulp and guava leaves were ground to fine powders using a mechanical grinder and packaged and well-sealed in polyethylene bags in polyethylene bags (each bag contains one about 250 gram) and exposed, at room temperature, to gamma irradiation at dose levels of 15,20 , and $30 \mathrm{kGy}$, as monitored by FWT-60-00 ${ }^{\mathrm{TM}}$ radio chromic film (ASTM, 2002 [ISO/ASTM 51275:2002(E)]). The irradiation facility used was the Indian Gamma Cell, delivered a dose rate of $1.2887 \mathrm{kGy}$ h-1 at the time of experimentation. The facility is located at the National Center for Radiation Research and Technology (NCRRT), Nasr City, Cairo, Egypt. The non-irradiated and irradiated samples were kept at $-20{ }^{\circ} \mathrm{C}$ until used.

\section{Preparation of extracts}

Water or $80 \%$ methanol was used for the preparation of the extracts. Dried fine powdered byproduct either pomegranate red peel, white pulp or guava leaves $(0.5 \mathrm{~g})$ was soaked in $5 \mathrm{ml}$ of the solvent and shaked then left overnight. Extraction was repeated for further two times by the same solvent then the volume was completed to $25 \mathrm{ml}$. All measurements were done for control and irradiated samples in triplicates and mean values were calculated.

\section{Total phenolic content:}

The total phenolic content was determined using Folin-Ciocolleu assay (27). The extract $(0.2 \mathrm{~mL})$, was mixed with $1 \mathrm{~mL}$ of 10 -fold diluted folin- 
ciocolleu reagent and $0.8 \mathrm{ml}$ of $7.9 \%$ Sodium carbonate solution. The mixture was allowed to stand for 30 minutes at room temperature; the absorbance was measured at $765 \mathrm{~nm}$. The concentration of total phenolics in all extracts was determined and results were expressed as gram of gallic acid equivalents per 100 grams of dry weight. (g GAE / 100 g DW).

\section{Total tannin content:}

Estimation of tannin was performed by titrating the extract with standard potassium permanganate solution following a previously reported method (28). Briefly $5 \mathrm{ml}$ aliquot of the extract was mixed with $12.5 \mathrm{ml}$ of indigo-carmine solution and $375 \mathrm{ml}$ of distilled water. The mixture was heated to $70{ }^{\circ} \mathrm{C}$ and titrated against $0.1 \mathrm{~N} \mathrm{kMnO}_{4}$ solution. As titration proceeded the color of the indigo-carmine was shown to pass through many shades to a final yellow with a faint pink tint in the rim. It was taken as the end-paint. This volume of $\mathrm{kMnO}_{4}(\mathrm{~A} \mathrm{ml})$ was used to titrate total tannin plus all other related compounds. To determine the volume of $\mathrm{kMnO}_{4}$ used to titrate non-tannin compounds, another aliquot of $5 \mathrm{ml}$ extract was mixed with $25 \mathrm{ml}$ of gelatin solution ( $25 \mathrm{~g}$ gelatin was soaked for 1 hour in saturated $\mathrm{NaCl}$ solution. The mixture was then warmed until the gelatin has dissolved and after cooling, the solution was made up to 1 liter with saturated $\mathrm{NaCl}$ ), $50 \mathrm{ml}$ of the acidic $\mathrm{NaCl}$ solution ( $25 \mathrm{ml}$ of concentrated $\mathrm{H}_{2} \mathrm{SO}_{4}$ was added to $975 \mathrm{ml}$ of saturated $\mathrm{NaCl}$ soln.) and $5 \mathrm{~g}$ powdered Kaolin. The mixture was shaken for 15 minutes and filtered. A volume of $12.5 \mathrm{ml}$ of the filtrate was mixed with same volume of Indigo carmine solution and $375 \mathrm{ml}$ of distilled water. The mixture was titrated by the same way against $\mathrm{kMnO} 4$ solution until color changed to faint pink as earlier and the volume of $\mathrm{kMnO}_{4}(\mathrm{~B} \mathrm{ml})$ was used to calculate the volume of $\mathrm{kMnO}_{4}$ used to titrate true tannin $(\mathrm{A}-\mathrm{B})$. The concentration of tannin was estimated using the following relationship:

$\%$ tannins =

$(\mathrm{A}-\mathrm{B}) * 250 * 100 *(0.00425 \mathrm{~g}$ tannins/mLof $0.1 \mathrm{~N} \mathrm{KMnO} 4)$ gm of sample powder $* \mathrm{~mL}$ of sample taken

$1 \mathrm{~mL}$ of standard $\mathrm{KMnO}_{4}$ solutions is equivalent to $0.00425 \mathrm{~g}$ of tannin as tannic acid.
Free
radical
scavenging
activity:

The free radical scavenging activity of the extracts was measured by DPPH using the method described by Su et al. (29). A volume of $0.05 \mathrm{ml}$ of each extract at different concentrations (10$40 \mu \mathrm{g} / \mathrm{ml}$ ) was mixed with $5 \mathrm{ml}$ of DPPH solution $(0.025 \mathrm{~g} / \mathrm{L})$ in methanol. A control containing DPPH solution only was also used. The absorbance was measured at $517 \mathrm{~nm}$ after 30 minutes of reaction at room temperature. The anti-radical scavenging activity was evaluated by measuring the decrease in absorbance.

$$
\begin{array}{ccc}
\% & \text { inhibition } & \text { control } \\
(\text { A control }- \text { A sample }) /(\text { A control }) * 100
\end{array}
$$

The percent inhibition data was then plotted against $\log$ concentration and $\mathrm{IC}_{50}$ (half maximal inhibitory concentration) value was calculated by linear regression analyses using SPSS software.

\section{Statistical analysis}

Statistical analysis was done using IBMc SPSSc Statistics version 22 (IBMc Corp., Armonk, NY, USA). Numerical data were expressed as mean and standard deviation. Data were tested for normality using Kolmogorov-Smirnov test and Shapiro-Wilk test. Data were found to be normally distributed so we used the parametric tests for comparison between groups. Comparison between more than two groups was done using analysis of variance (ANOVA) then post-Hoc "Tukey HSD test" was used for pair-wise comparison. Paired t-test was used to compare aqueous and methanolic extracts. All tests were two-tailed. A p-value $<0.05$ was considered significant.

\section{Results}

The effect of radiation on the total phenolic content of the by-products studied is shown in Table (1).At zero irradiation dose, the total phenolic content of the red peel was 3.62 and $3.71 \mathrm{~g} \mathrm{GAE} / 100 \mathrm{~g}$ DW for the aqueous and methanolic extracts, respectively. For the white pulp, the values were 3.61 and $3.65 \mathrm{~g}$ GAE/100g DW for the aqueous and methanolic extracts, respectively. Guava leaves gave 3.43 and 4.20 for the aqueous and methanolic extracts respectively. In case of the red peel, no significant 
change was noticed due to irradiation at all doses for both solvents. The white pulp showed a decrease in the total phenolic content at irradiation dose of $30 \mathrm{kGy}$ for the aqueous extract. The methanolic extract showed an increase at $15 \mathrm{kGy}$. The phenolic content of the aqueous extract of guava leaves was higher at $15 \mathrm{kGy}$ compared with the non-irradiated sample. Decreased total phenolic content was noticed for the methanolic extract of guava leaves at $30 \mathrm{kGy}$.

The total tannin content for the by-products studied is shown in Table (2). At zero irradiation dose, the red peel gave 1.83 and $1.99 \mathrm{~g}$ TAE/100g DW for the aqueous and methanolic extracts respectively. The white pulp showed 2.14 and $2.59 \mathrm{~g}$ TAE/100g DW for the aqueous and methanolic extracts respectively. In case of guava leaves, the total tannin content was 0.97 and $1.16 \mathrm{~g}$ TAE/100g DW for the aqueous and methanolic extracts respectively. The effect of irradiation dose indicated that, in case of the red peel, there was a significant decrease at $15 \mathrm{kGy}$ then an increase at $20 \mathrm{kGy}$ for the aqueous extract. No significant change was noticed in case of the methanolic extract. The extracts of the irradiated white pulp showed a decrease in total tannin content in both aqueous and methanolic extracts at all irradiation doses compared with the non-irradiated samples. In case of guava leaves, an increase in the total tannin content was recorded for the aqueous extract at 20 and $30 \mathrm{kGy}$ and for methanolic extract at $20 \mathrm{kGy}$.

The inhibition percentage of DPPH radical scavenging activity is shown in Table (3).At zero irradiation dose, the red peel gave 79.41 and $92.49 \%$ for the aqueous and methanolic extracts respectively. The white pulp showed inhibition of 92.94 and $96.55 \%$ for the aqueous and methanolic extracts respectively. For guava leaves, the values were 93.23 and 96.80 for the aqueous and methanolic extracts respectively. A significant increase in the percent DPPH radical scavenging activity was recorded for the aqueous extract of the red peel at 30kGy and for the methanolic extracts at all irradiation doses. A reduction was noticed in the extracts of both solvents in case of the white pulp at all irradiation doses. No significant change was found between the extracts of the non-irradiated guava leaves and the extracts of irradiated samples at all irradiation doses. In case of the aqueous extracts, a significant change was noticed between samples at 15 and $30 \mathrm{kGy}$ (Lower values were obtained at $30 \mathrm{kGy}$ ). The results for the IC50 are shown in Table (8) and Fig. (1-6).The methanolic extract of the non-irradiated guava leaves gave the lowest value(the highest antioxidant activity), followed by the methanolic extract of the nonirradiated red peel.

The effect of solvent showed that higher total phenolic content was reported for the methanolic extracts of the red peel at zero and guava leaves at $20 \mathrm{kGy}$ compared with the aqueous extracts. The total tannin content was higher in the methanolic extracts of the red peel at $15 \mathrm{kGy}$ and guava leaves at zero and $20 \mathrm{kGy}$.The effect of the solvent on the DPPH radical scavenging activity indicated that higher value (and lower IC50) were noticed in almost all methanolic extracts compared with the aqueous extracts as shown in Tables (4-7).

\section{Discussion}

The present results indicated that both nonirradiated and irradiated by-products possessed excellent antioxidant activity. The experimental data revealed that irradiation itself did not cause dramatic changes or that the changes or that the changes were, at least, comparable. This is in agreement with that reported by Polovka\&Suhaj2013(30).

At zero irradiation dose, the total phenolic content of the red peel was 3.62 and $3.71 \mathrm{~g} \mathrm{GAE} / 100 \mathrm{~g}$ for the aqueous and methanolic extracts respectively. These Values are comparable with the results obtained by Manasathien et al.,2012(31) who found that the phenolic content of pomegranate peel was 3.80 and $4.49 \mathrm{~g} \mathrm{GAE} / 100 \mathrm{~g}$ for the aqueous and ethanolic extracts, respectively. Li et al.,2006(32) extracted the pomegranate peel with different solvents including methanol, ethanol, acetone and all extracts were pooled together and concentrated under vaccum at $6^{\circ} \mathrm{C}$ and powdered then dissolved in water. The phenolic content was found to be 24.94 g TAE/100g.Several other investigators gave variable results. Elfalleh et al.,2012 (33) reported values of 5.36 and $8.56 \mathrm{~g} \mathrm{GAE} / 100 \mathrm{~g}$ for the aqueous and methanolic extracts, respectively, ViudaMartosin et al.,2013(34) got a value of $4.48 \mathrm{~g}$ GAE/100g for the methanolic extract, Dadwal et al.,2017(35) obtained a value of $5.89 \mathrm{~g} \mathrm{GAE} / 100 \mathrm{~g}$ for the ethanolic extract and Mekni et al.,2018(36) found values ranging from 10.47-14.44 $\mathrm{g}$ GAE/100g in the methanolic extracts of peels of five pomegranate varieties. A comparative evaluation of pomegranate in different world regions was published by Bassiri and Doostkam 
2019 (37). In their study, the phenolic content of pomegranate peel of various pomegranate cultivars ranged from 25-29.55 g GAE/100g. The authors indicated that the peels have significant superior antioxidant activity compared to other parts of pomegranate.

The total tannin content in the red peel was 1.83 and $1.99 \mathrm{~g} \mathrm{TAE} / 100 \mathrm{~g}$ for the aqueous and methanolic extracts respectively. Elfalleh et al.,2012 (33) indicated values of 6.27 and $13.96 \mathrm{~g}$ TAE/100g. Kushwaha et al.,2013(38) found that the phenolic content of pomegranate peel was $4.053 \mathrm{~g}$ GAE /100g, while for the detanninated sample was $0.11 \mathrm{~g} \mathrm{GAE} / 100 \mathrm{~g}$. This indicated that tannins represented about $97 \%$ of the phenolic content.

The DPPH radical scavenging activity of the nonirradiated red peel indicated that the percent DPPH inhibition was 79.41 and 92.49 for the aqueous and methanolic extracts, respectively. Shiban 2012(39) reported values ranging from $34.3 \%-75.4 \%$ and from $46.3 \%-99.3 \%$ for the aqueous and methanolic extracts respectively with increasing the concentration from $12.5-50 \mu \mathrm{g} / \mathrm{ml}$. The authors indicated that the DPPH radical scavenging activity of the methanolic extract was also stronger than that of catechin. Mahmoud\&Ibrahim 2013(40) Indicated values ranging from $75 \%-82 \%$ for the methanolic extract of some Egyptian pomegranate cultivars compared to $75 \%$ for the synthetic preservative butylated hydroxyl anisol (BHA) and $79 \%$ for tert-butyl hydroquinone (TBHQ).They indicated that pomegranate peel extract at a concentration of $800-850 \mathrm{ppm}$ has a stabilizing effect comparable to synthetic antioxidants namely butylated-hydroxyl toluene (BHT) at its legal limit. AL. Mashkor 2014(41) compared the DPPH scavenging activity of pomegranate peel using different solvents and the most effective radical scavenging activity was shown by $50 \%$ acetone. Jeevarathinam and Muthulakshmi 2017 (42) found a value of $43.24 \%$ for aqueous extract and Mehrizi 2017 (43) found a value of $63.86 \%$ for the ethanolic extract of pomegranate peel. Guo et al., 2003(44) reported that of 28 fruit peels analyzed, the pomegranate peel displayed the highest antioxidant activity. Kaur and Kapoor 2002(45) studied the antioxidant activity of some Asian plants and classified the plants studied according to the activity into high (70\%-92\%), medium (62\%-69\%) and low (12\%-57\%).

The $\mathrm{IC}_{50}$ of the red peel at zero irradiation dose was $5.12 \mu \mathrm{g} / \mathrm{ml}$ for the aqueous extract and $0.79 \mu \mathrm{g} / \mathrm{mL}$ for the methanolic extract. Okonogi et al.,2007(46) got a value of $3 \mu \mathrm{g} / \mathrm{ml}$ for the aqueous extract of pomegranate peel. Other investigators indicated values of $4.9 \mu \mathrm{g} / \mathrm{ml}$ for the aqueous extract (47), 135 $\mu \mathrm{g} / \mathrm{mL}$ for the aqueous and $105 \mu \mathrm{g} / \mathrm{ml}$ for the ethanolic extract (48), $302 \mu \mathrm{g} / \mathrm{ml}$ for ethyl acetate extract (49), $6.12 \mu \mathrm{g} / \mathrm{ml}$ for the ethanolic extract (50) and $16.78 \mu \mathrm{g} / \mathrm{mL}$ for the ethanolic extract (51). Pyrzynska and Pekal 2013(52) discussed the reason for the diversity of the results published for similar samples and indicated that the experiments are usually performed under different chemical conditions and that for the most of the compounds which exhibit antioxidant activities, their reaction with DPPH is biphasic, with a fast decay in absorbance in the first few minutes, followed by a slower step in which degradation products are involved, until the equilibrium is reached. The authors indicated also that different values of $\mathrm{IC}_{50}$ could be found in the literature for the same compounds and this parameter highly depends on the reaction time and the initial DPPH concentration.

There is relatively little published work on pomegranate white pulp (mesocarp) and guava leaves. Ambigaipalan 2016(53) studied the phenolic compounds and antioxidant activity of the outer skin (Red peel) and the mesocarp (white pulp) of pomegranate. In agreement with the present results, the outer skin had higher phenolic content and DPPH inhibition than the mesocarp. When estrfied phenols and bound phenols were added; the mesocarp was higher than the outer skin. In a study carried out by Khatib et al.,2017 (54) the mesocarp and exocarp of Laffan and wonderful pomegranate varieties were tested for their content of ellagotannins. The results indicated that the profile of mesocarp and exocarp separately of the two varieties was similar and that the highest ellagotannins amount was obtained from the mesocarp. The effect of albedo addition (white pulp) to pomegranate juice was studied by Vázquez et al.,2011\&2015(55\&56). The authors reported a significantly higher total phenolic content with only slight difference in sensory properties and concluded that adding albedo to juice could be a good tool to increase healthy properties without decreasing the acceptabilty of the product.

The antioxidant activity of guava leaf extract was studied (57).The study showed a remarkably high phenolic content (51.16 and 57.53 g GAE/100g) for the aqueous and ethanolic extracts, respectively. 
Chen and Yen 2007(58) found values of total phenolic content of aqueous extracts from cultivars of guava leaves and two kinds of guava tea ranging from 16.60-48.30 g GAE/100g.All showed over $85 \%$ radical scavenging activity. In the present results, all samples had over $90 \%$ radical scavenging activity. Vyas et al.,2010 (59) got $45 \mu \mathrm{g} / \mathrm{ml}$ for the $\mathrm{IC}_{50}$ of the ethanolic extract compared to $25.8 \mu \mathrm{g} / \mathrm{ml}$ for ascorbic acid. Venkatachalam et al.,2012(60) indicated a phenolic content of 0.70 and $0.80 \mathrm{~g} \mathrm{GAE} / 100 \mathrm{~g}$ for the aqueous and methanolic extracts respectively, and a tannin content of $0.35 \mathrm{~g}$ TAE $/ 100 \mathrm{~g}$ for the aqueous and $0.38 \mathrm{~g}$ TAE$/ 100 \mathrm{~g}$ for the methanolic extract. A tannin content of $0.23 \mathrm{~g}$ GAE $/ 100 \mathrm{~g}$ for the ethanolic extract of guava leaves was attained by Mailoa et al.,2014(61). Lamjud et al.,2014(62) indicated a total phenolic content of $5.30 \mathrm{~g}$ $\mathrm{GAE} / 100 \mathrm{~g}$ in the methanolic extract. Irondi et al.,2016(63) showed IC50 of $13.38 \mu \mathrm{g} / \mathrm{ml}$ for the ethanolic extract of guava leaves compared to 7.38 $\mu \mathrm{g} / \mathrm{ml}$ for ascorbic acid.

In a study carried out by Akila et al.,2018 (64) total phenolic content of the aqueous extract of guava leaves was $9.92 \mathrm{~g} \mathrm{GAE} / 100 \mathrm{~g}$, total tannin content was $0.29 \mathrm{~g}$ GAE/100g and DPPH scavenging activity was $71 \%$. The results of the phytochemical analysis carried out by Das et al., 2019 (65) revealed that guava leaf extract was rich in phenols and tannins and that this is the cause of the antimicrobial property of guava leaves. In their results, the inhibitory concentration $\left(\mathrm{IC}_{50}\right)$ was 1.56 $\mu \mathrm{g} / \mathrm{ml}$ for absolute alcohol extract, 1.72 for $70 \%$ ethanolic and 4.10 for $50 \%$ ethanolic extract.

The effect of irradiation dose on the antioxidant compounds and activity is shown in Tables (1-3) and Figs. (1-6). One of the very rare publications about this subject was performed by Mali et al.,2011(3), Where pomegranate peel powder samples were exposed to gamma irradiation at various levels of 5,10,15 and $25 \mathrm{kGy}$. The effect of irradiation on total phenolic content and in vitro antioxidant activity along with microbial decontamination was studied for all the irradiated and control (0 kGy) methanolic extracts samples. They indicated that at a radiation dose of $10 \mathrm{kGy}$, the total phenolic content and average in vitro antioxidant activity were increased by $4 \%$ and $12 \%$, respectively. The authors explained the increase in total phenolic content due to the degradation of tannins present in pomegranate peel having higher molecular weight and the release of simple phenolic compounds Bhat et al.,2007(66) studied the effect of radiation on antinutritional features of Velvet bean seed and indicated that, except for $25 \mathrm{kGy}$, all doses showed a significant dose-dependent increase in total phenolic contents and that this was due to the higher extrability by depolymerisation and dissolution of cell wall polysaccharides by irradiation, which was known to increase the activity of phenyl alanine ammonia-lyase responsible for synthesis of phenolic compounds. In the present results no significant change was noticed in the phenolic content of both aqueous and methanolic extracts of pomegranate red peel while the radical scavenging activity was shown to increase at a dose of $30 \mathrm{kGy}$ in the aqueous and at all irradiation doses for the methanolic extract. In case of the white pulp, a decrease in the total phenolic content was noticed at $30 \mathrm{kGy}$ for the aqueous and an increase at $15 \mathrm{kGy}$ for the methanolic extract. A reduction in the total phenolic content was noticed in guava leaf extract at $15 \mathrm{kGy}$ for the aqueous and at 20 and $30 \mathrm{kGy}$ for the methanolic extract. Gumus et al.,2011(67) indicated that the total phenolic content of the methanolic extracts of three spices from turkey was found to decrease with irradiation except at $5.1 \mathrm{kGy}$ for one of the spices studied, and that the DPPH radical scavenging activity of the extracts decreased after irradiation. In the present results, a decrease in the DPPH radical scavenging activity was noticed only in case of the white pulp at all irradiation doses compared to non-irradiated samples.

Variyar et al.,1998(68) studied the phenolic acids of some irradiated spices and indicated that quantitavely significant changes were noted upon irradiation and some phenolic acids increased by 2.2 to 4.4 fold and that in some other irradiated spices many of the phenolic acids showed wide increase and decrease in the range of two to six fold compared with the control samples. In agreement with the present results, Polovka \&Suhaj2013(30) showed that experimental data revealed that gamma irradiation did not cause any dramatic change in the total phenolic content and antioxidant activity of some commercial herbs. Gustavo et al.,2013(69) did not find any significant change in the total phenolic content in the methanolic extract of bark of Spondias Luta $\mathrm{L}$ at irradiation doses of 5, 10, 15 and $20 \mathrm{kGy}$. This is in agreement with the results of the red peel in the present work.

Several studies were carried out about the effect of gamma irradiation on the tannin content of some 
plant foods as antinutrient. (70-74).These authors showed a reduced tannin content after irradiation, which they considered one of the benefits of irradiation on the nutritional properties of the foodstuffs studied. The reduction of tannin content in the present study was obvious in case of the white pulp where a significant decrease was noticed in both aqueous and methanolic extracts at all irradiation doses compared with the non-irradiated samples. For the rest of by-products, variable results for tannin content were obtained including no change either increase or decrease. Janiak et al.,2017(75), during their study about the effect of gamma irradiation on the antioxidant potential of traditional Bulgarian tea, showed that irradiation increased the tannin content in planinski tea and decreased it in Good night tea. Tannin content was shown to increase in soy beans (76), and peanut skins (77) after gamma irradiation. In addition, radiation can convert the B-type procyanidin dimer into the A-type (75).

In this work, the DPPH radical scavenging activity was shown to increase in case of the aqueous extract of the red peel at $30 \mathrm{kGy}$ and the methanolic extract at all irradiation doses. In case of the white pulp a reduction was noticed at all irradiation doses for both solvents which was parallel to the tannin content. In case of guava leaves, a very high activity was shown by all samples including the control and at all irradiation doses. The activity ranged from $92.52 \%$ to $97.42 \%$ without any significant change due to irradiation. The IC50 was the lowest (highest activity) in case of guava leaves where it ranged from 0.17 to 4.36 $\mu \mathrm{g} / \mathrm{ml}$ compared to from 0.79 to $5.69 \mu \mathrm{g} / \mathrm{ml}$ in case of the red peel and from 3.05 to $5.70 \mu \mathrm{g} / \mathrm{ml}$ in case of the white pulp.

The effect of solvent indicated that the methanolic extracts were higher in total phenolic content in case of red peel at zero irradiation dose and guava leaves at $30 \mathrm{kGy}$. The tannin content showed a higher value in the methanolic extracts of the red peel at $15 \mathrm{kGy}$ and guava leaves at zero and20kGy.In the rest of samples there was no significant change in the total phenolic content or tannin content between the aqueous and methanolic extracts. The effect of solvent on the DPPH radical scavenging activity showed that almost all methanolic extracts gave higher values than the aqueous extracts. This is in agreement with Pereira et al.,2014(78) during their study about the effect of irradiation on antioxidant properties of Borututu which is a well known medicinal plant. They indicated also that higher values were given at irradiation dose of $10 \mathrm{kGy}$ in both aqueous and methanolic extracts. A similar study was carried out by Sallam and Anwar (79) on Portulaca oleracea plant, where they found higher values for the methanolic extract compared to the aqueous or ethanolic extracts. They also showed that higher values were obtained at a radiation dose of $9 \mathrm{kGy}$ in all extracts compared to the nonirradiated samples. In the present work methanolic extracts gave higher values but the effect of irradiation on both extracts was not always the same. Although the majority of studies indicated higher values for the alcoholic extracts, some studies showed higher phenolic content, tannin content or antioxidant activity in case of water extracts compared to alcoholic extracts $(48,80,81)$.

The antioxidant properties of extracts from the food samples using different solvents were discussed in some previous investigations (8285).Pyrzynska and Pekal 2013 (52) reported that the antioxidant properties of such extracts are largely related to differences in their quantitative and qualitative composition resulting from different extraction ability of the used solvents and that antioxidant compounds in food may be water soluble, fat soluble, insoluble or bound to cell wall.

In conclusion, all the by-products studied had reasonable contents of total phenols, tannins and high antioxidant activities. The effect of irradiation showed higher antioxidant activity in case of the red peel, lower values in case of the white pulp after irradiation. No significant change in the antioxidant activity of guava leaves being extremely high in all samples at all doses without any significant change between non-irradiated and irradiated samples. Even in case of the white pulp, which showed the lowest values, it retained most of its activity after irradiation (more than $70 \%$ of its natural activity). Calculation of the IC50 confirmed these results, but it was not exactly parallel to the DPPH radical scavenging activity at a fixed concentration $(40 \mu \mathrm{g} / \mathrm{ml})$.

The study recommends using these by-products as food preservatives, supplementary feeds for animals and in preparation of pharmacological products. Guava leaf extract from stabilized guava leaves by irradiation seem to be the best as a preservative being the highest in antioxidant activity. 
Table (1): Effect of Gamma irradiation dose(kGy) on total phenolic content (as GAE/100g Dw) of the fruit byproducts studied (mean \pm SD)

\begin{tabular}{c|cc|c|c|c|c}
\hline \multirow{2}{*}{$\begin{array}{c}\text { Dose } \\
(\mathrm{kGy})\end{array}$} & \multicolumn{6}{c}{ Total phenolic content (as GAE/100g DW) } \\
\cline { 2 - 7 } & Red peel & \multicolumn{2}{c}{ White pulp } & \multicolumn{2}{c}{ Guava leaves } \\
\cline { 2 - 7 } & Aqueous & Methanolic & Aqueous & Methanolic & Aqueous & Methanolic \\
\hline 0 & $3.62 \pm 0.07^{\mathrm{a}}$ & $3.71 \pm 0.04^{\mathrm{a}}$ & $3.61 \pm 0.02^{\mathrm{a}}$ & $3.65 \pm 0.05^{\mathrm{a}}$ & $3.43 \pm 0.16^{\mathrm{a}}$ & $4.20 \pm 0.43^{\mathrm{a}}$ \\
15 & $3.53 \pm 0.36^{\mathrm{a}}$ & $3.95 \pm 0.09^{\mathrm{a}}$ & $4.01 \pm 0.20^{\mathrm{ac}}$ & $4.47 \pm 0.25^{\mathrm{b}}$ & $2.24 \pm 0.11^{\mathrm{b}}$ & $4.31 \pm 0.06^{\mathrm{a}}$ \\
20 & $3.51 \pm 0.38^{\mathrm{a}}$ & $3.87 \pm 0.14^{\mathrm{a}}$ & $3.49 \pm 0.27^{\mathrm{ab}}$ & $3.31 \pm 0.24^{\mathrm{a}}$ & $3.56 \pm 0.10^{\mathrm{a}}$ & $3.73 \pm 0.10^{\mathrm{ab}}$ \\
30 & $4.02 \pm 0.01^{\mathrm{a}}$ & $4.22 \pm 0.37^{\mathrm{a}}$ & $3.07 \pm 0.04^{\mathrm{b}}$ & $3.39 \pm 0.31^{\mathrm{a}}$ & $3.37 \pm 0.26^{\mathrm{a}}$ & $3.49 \pm 0.19^{\mathrm{b}}$ \\
\hline
\end{tabular}

Values having different letters in the same column are significantly different $(p<0.05)$.

Table (2): Effect of Gamma irradiation dose(kGy) on total tannins content (as TAE/100gDw) of the fruit by-products studied

\begin{tabular}{|c|c|c|c|c|c|c|}
\hline \multirow{3}{*}{$\begin{array}{l}\text { Dose } \\
\text { (kGy) }\end{array}$} & \multicolumn{6}{|c|}{ Total tannins content (as TAE/100g DW) } \\
\hline & \multicolumn{2}{|c|}{ Red peel } & \multicolumn{2}{|c|}{ White pulp } & \multicolumn{2}{|c|}{ Guava leaves } \\
\hline & Aqueous & Methanolic & Aqueous & Methanolic & Aqueous & Methanolic \\
\hline 0 & $1.83 \pm 0.10^{\mathrm{a}}$ & $1.99 \pm 0.30^{\mathrm{a}}$ & $2.14 \pm 0.31^{\mathrm{a}}$ & $2.59 \pm 0.51^{\mathrm{a}}$ & $0.97 \pm 0.04^{\mathrm{a}}$ & $1.16 \pm 0.09^{a}$ \\
\hline 15 & $1.52 \pm 0.10^{b}$ & $2.28 \pm 0.01^{a}$ & $1.46 \pm 0.13^{b}$ & $1.51 \pm 0.14^{b}$ & $1.01 \pm 0.11^{\mathrm{ab}}$ & $1.02 \pm 0.07^{a}$ \\
\hline 20 & $2.24 \pm 0.10^{c}$ & $2.35 \pm 0.17^{\mathrm{a}}$ & $1.12 \pm 0.03^{b}$ & $1.18 \pm 0.03^{b}$ & $1.24 \pm 0.11^{\mathrm{b}}$ & $1.60 \pm 0.11^{b}$ \\
\hline 30 & $1.63 \pm 0.04^{\mathrm{ab}}$ & $1.38 \pm 0.17^{a}$ & $1.05 \pm 0.12^{b}$ & $1.19 \pm 0.02^{b}$ & $1.22 \pm 0.11^{b}$ & $1.17 \pm 0.26^{\mathrm{a}}$ \\
\hline
\end{tabular}

Values having different letters in the same column are significantly different $(\mathrm{p}<0.05)$

Table (3): Effect of Gamma irradiation dose on DPPH scavenging activity of the fruit by-products studied (mean \pm SD)

\begin{tabular}{|c|c|c|c|c|c|c|}
\hline \multirow{3}{*}{$\begin{array}{c}\text { Dose } \\
(\mathrm{kGy})\end{array}$} & \multicolumn{6}{|c|}{ Percent inhibition (at $40 \mu \mathrm{g} / \mathrm{ml}$ ) } \\
\hline & \multicolumn{2}{|c|}{ Red peel } & \multicolumn{2}{|c|}{ White pulp } & \multicolumn{2}{|c|}{ Guava leaves } \\
\hline & Aqueous & Methanolic & Aqueous & Methanolic & Aqueous & Methanolic \\
\hline 0 & $79.14 \pm 2.194^{\mathrm{a}}$ & $92.49 \pm 0.52^{\mathrm{a}}$ & $92.61 \pm 1.70^{\mathrm{a}}$ & $96.55 \pm 1.412^{\mathrm{a}}$ & $93.23 \pm 1.319^{\mathrm{a}}$ & $96.8 \pm 1.731^{\mathrm{a}}$ \\
\hline 15 & $79.62 \pm 0.788^{\mathrm{ac}}$ & $96.64 \pm 0.79^{b}$ & $76.82 \pm 1.88^{\mathrm{bc}}$ & $91.93 \pm 1.451^{\mathrm{bc}}$ & $96.71 \pm 1.646^{\mathrm{ab}}$ & $96.17 \pm 1.17^{\mathrm{a}}$ \\
\hline 20 & $83 \pm 1.953^{\mathrm{abc}}$ & $96.31 \pm 1.868^{\mathrm{b}}$ & $68.82 \pm 2.059^{\mathrm{bd}}$ & $83.33 \pm 1.361^{\mathrm{bd}}$ & $92.83 \pm 1.634^{\mathrm{abd}}$ & $96.5 \pm 1.416^{\mathrm{a}}$ \\
\hline 30 & $85.29 \pm 1.94^{\mathrm{b}}$ & $96.12 \pm 1.396^{\mathrm{b}}$ & $65.35 \pm 0.934^{\mathrm{bd}}$ & $81.95 \pm 1.772^{\text {bd }}$ & $92.52 \pm 1.434^{\mathrm{ad}}$ & $97.42 \pm 1.279^{\mathrm{a}}$ \\
\hline
\end{tabular}

Values having different letters in the same column are significantly different $(\mathrm{p}<0.05)$. 
Table (4): Effect of solvent on total phenolic content, total tannin content and \% DPPH scavenging activity of the fruit byproducts studied at irradiation dose of $0 \mathrm{kGy}($ mean \pm SD)

\begin{tabular}{|c|c|c|c|c|c|c|c|c|c|}
\hline \multirow[t]{2}{*}{ Sample } & \multicolumn{3}{|c|}{$\begin{array}{l}\text { Total phenolic } \\
\text { (GAE/100g DW) }\end{array}$} & \multicolumn{3}{|c|}{$\begin{array}{c}\text { Tannins } \\
(\mathrm{TAE} / 100 \mathrm{~g} \text { DW) }\end{array}$} & \multicolumn{3}{|c|}{$\begin{array}{c}\text { DPPH } \\
\text { (at } 40 \mu \mathrm{g} / \mathrm{ml} \text { ) }\end{array}$} \\
\hline & Aqueous & Methanolic & $\mathrm{P}$ & Aqueous & Methanolic & $\mathrm{P}$ & Aqueous & Methanolic & $\mathrm{P}$ \\
\hline Red peel & $3.62 \pm 0.07$ & $3.71 \pm 0.04$ & $<0.05$ & $1.83 \pm 0.10$ & $1.99 \pm 0.30$ & $>0.05$ & $79.14 \pm 2.194$ & $92.49 \pm 0.52$ & $<0.05$ \\
\hline $\begin{array}{l}\text { White } \\
\text { pulp }\end{array}$ & $3.61 \pm 0.02$ & $3.65 \pm 0.05$ & $>0.05$ & $2.14 \pm 0.31$ & $2.59 \pm 1.50$ & $>0.05$ & $92.61 \pm 1.71$ & $96.55 \pm 1.42$ & $>0.05$ \\
\hline $\begin{array}{l}\text { Guava } \\
\text { leaves }\end{array}$ & $3.43 \pm 0.16$ & $4.20 \pm 0.43$ & $>0.05$ & $0.90 \pm 0.04$ & $1.16 \pm 0.09$ & $<0.05$ & $93.23 \pm 1.39$ & $96.8 \pm 1.731$ & $<0.05$ \\
\hline
\end{tabular}

significant difference $(\mathrm{p}<0.05)$

Table (5): Effect of solvent on total phenolic content, total tannin content and \% DPPH scavenging activity of the fruit byproducts studied at irradiation dose of $15 \mathrm{kGy}($ mean \pm SD)

\begin{tabular}{|c|c|c|c|c|c|c|c|c|c|}
\hline \multirow{2}{*}{ Sample } & \multicolumn{3}{|c|}{$\begin{array}{l}\text { Total phenolic } \\
(\mathrm{GAE} / 100 \mathrm{~g} \text { DW) }\end{array}$} & \multicolumn{3}{|c|}{$\begin{array}{c}\text { Tannins } \\
\text { (TAE/ 100g DW) }\end{array}$} & \multicolumn{3}{|c|}{$\begin{array}{c}\text { DPPH } \\
\text { (at } 40 \mu \mathrm{g} / \mathrm{ml} \text { ) }\end{array}$} \\
\hline & $\begin{array}{c}\text { Aqueou } \\
\mathrm{s}\end{array}$ & $\begin{array}{l}\text { Methanol } \\
\text { ic }\end{array}$ & $\mathrm{P}$ & Aqueous & Methanolic & $\mathrm{P}$ & Aqueous & Methanolic & $\mathrm{P}$ \\
\hline Red peel & $3.53 \pm 0.36$ & $3.95 \pm 0.09$ & $>0.05$ & $1.52 \pm 0.10$ & $2.28 \pm 0.01$ & $<0.05$ & $79.62 \pm 0.788$ & $96.64 \pm 0.79$ & $<0.05$ \\
\hline White pulp & $4.01 \pm 0.20$ & $4.47 \pm 0.25$ & $>0.05$ & $1.46 \pm 0.13$ & $1.51 \pm 0.14$ & $>0.05$ & $76.82 \pm 1.88$ & $91.93 \pm 1.451$ & $<0.05$ \\
\hline $\begin{array}{l}\text { Guava } \\
\text { leaves }\end{array}$ & $4.24 \pm 0.11$ & $4.31 \pm 0.06$ & $>0.05$ & $1.01 \pm 0.11$ & $1.02 \pm 0.07$ & $>0.05$ & $96.71 \pm 1.646$ & $96.5 \pm 1.17$ & $>0.05$ \\
\hline
\end{tabular}

significant difference $(\mathrm{p}<0.05)$

Table (6): Effect of solvent on total phenolic content, total tannin content and \% DPPH scavenging activity of the fruit by products studied at irradiation dose of $20 \mathrm{kGy}$ (mean \pm SD)

\begin{tabular}{c|c|c|c|c|c|c|c|c|c}
\hline \multirow{2}{*}{$\begin{array}{c}\text { Sample } \\
\end{array}$} & \multicolumn{2}{|c}{$\begin{array}{c}\text { Total phenolic } \\
\text { (GAE/100g DW) }\end{array}$} & \multicolumn{2}{c|}{$\begin{array}{c}\text { Tannins } \\
\text { (TAE/100g DW) }\end{array}$} & \multicolumn{3}{c}{$\begin{array}{c}\text { DPPH } \\
\text { (at } 40 \mu \mathrm{g} / \mathrm{ml})\end{array}$} \\
\cline { 2 - 10 } & Aqueous & Methanolic & $\mathrm{P}$ & Aqueous & Methanolic & P & Aqueous & Methanolic & P \\
\hline $\begin{array}{c}\text { Red } \\
\text { peel }\end{array}$ & $3.51 \pm 0.36$ & $3.87 \pm 0.14$ & $>0.05$ & $2.24 \pm 0.10$ & $2.35 \pm 0.17$ & $>0.05$ & $83 \pm 1.953$ & $96.31 \pm 1.868$ & $<0.05$ \\
White & $3.49 \pm 0.27$ & $3.31 \pm 0.24$ & $>0.05$ & $1.12 \pm 0.03$ & $1.18 \pm 0.03$ & $>0.05$ & $68.82 \pm 2.059$ & $83.33 \pm 1.361$ & $<0.05$ \\
pulp & & & & & & & & & \\
$\begin{array}{c}\text { Guava } \\
\text { leaves }\end{array}$ & $3.56 \pm 0.10$ & $3.73 \pm 0.10$ & $<0.05$ & $1.24 \pm 0.11$ & $1.60 \pm 0.11$ & $<0.05$ & $92.83 \pm 1.634$ & $96.5 \pm 1.416$ & $<0.05$ \\
\hline
\end{tabular}

significant difference $(\mathrm{p}<0.05)$ 
Table (7) : Effect of solvent on total phenolic content, total tannin content and \% DPPH scavenging activity of the fruit by products studied at irradiation dose of $30 \mathrm{kGy}$ (mean \pm SD)

\begin{tabular}{|c|c|c|c|c|c|c|c|c|c|}
\hline \multirow[t]{2}{*}{ Sample } & \multicolumn{3}{|c|}{$\begin{array}{c}\text { Total phenolic } \\
\text { (GAE/100g DW) }\end{array}$} & \multicolumn{3}{|c|}{$\begin{array}{c}\text { Tannins } \\
(\mathrm{TAE} / 100 \mathrm{~g} \mathrm{DW})\end{array}$} & \multicolumn{3}{|c|}{$\begin{array}{c}\text { DPPH } \\
\text { (at } 40 \mu \mathrm{g} / \mathrm{ml} \text { ) }\end{array}$} \\
\hline & Aqueous & Methanolic & $P$ & Aqueous & Methanolic & $\mathrm{P}$ & Aqueous & Methanolic & $\mathrm{P}$ \\
\hline Red peel & $4.02 \pm 0.01$ & $4.22 \pm 0.37$ & $>0.05$ & $1.63 \pm 0.04$ & $1.88 \pm 0.17$ & $>0.05$ & $85.29 \pm 1.94$ & $96.12 \pm 1.396$ & $<0.05$ \\
\hline $\begin{array}{l}\text { White } \\
\text { pulp }\end{array}$ & $3.07 \pm 0.04$ & $3.39 \pm 0.31$ & $>0.05$ & $1.05 \pm 0.12$ & $1.19 \pm 0.02$ & $>0.05$ & $65.35 \pm 0.934$ & $81.95 \pm 1.772$ & $<0.05$ \\
\hline $\begin{array}{l}\text { Guava } \\
\text { leaves }\end{array}$ & $3.37 \pm 0.26$ & $3.49 \pm 0.19$ & $>0.05$ & $1.22 \pm 0.11$ & $1.17 \pm 0.26$ & $>0.05$ & $92.52 \pm 1.434$ & $97.42 \pm 1.279$ & $<0.05$ \\
\hline
\end{tabular}

significant difference $(\mathrm{p}<0.05)$

Table (8): Effect of Gamma irradiation dose on $\mathrm{IC}_{50}$ of the fruit by-products studied

\begin{tabular}{c|c|c|c|c|c|c}
\hline \multirow{2}{*}{$\begin{array}{c}\text { Dose } \\
(k G y)\end{array}$} & \multicolumn{6}{|c|}{ DPPH IC $50(\mu \mathrm{g} / \mathrm{ml})$} \\
\cline { 2 - 7 } & \multicolumn{2}{|c|}{ Red peel } & \multicolumn{2}{c}{ White pulp } & \multicolumn{2}{c}{ Guava leaves } \\
\cline { 2 - 7 } & Aqueous & Methanolic & Aqueous & Methanolic & Aqueous & Methanolic \\
\hline 0 & 5.121 & 0.789 & 4.672 & 3.051 & 2.197 & 0.172 \\
15 & 4.917 & 2.809 & 5.448 & 3.677 & 2.587 & 1.148 \\
20 & 5.131 & 2.856 & 5.699 & 4.033 & 3.423 & 1.922 \\
30 & 5.692 & 2.618 & 4.643 & 4.295 & 4.362 & 1.140 \\
\hline
\end{tabular}
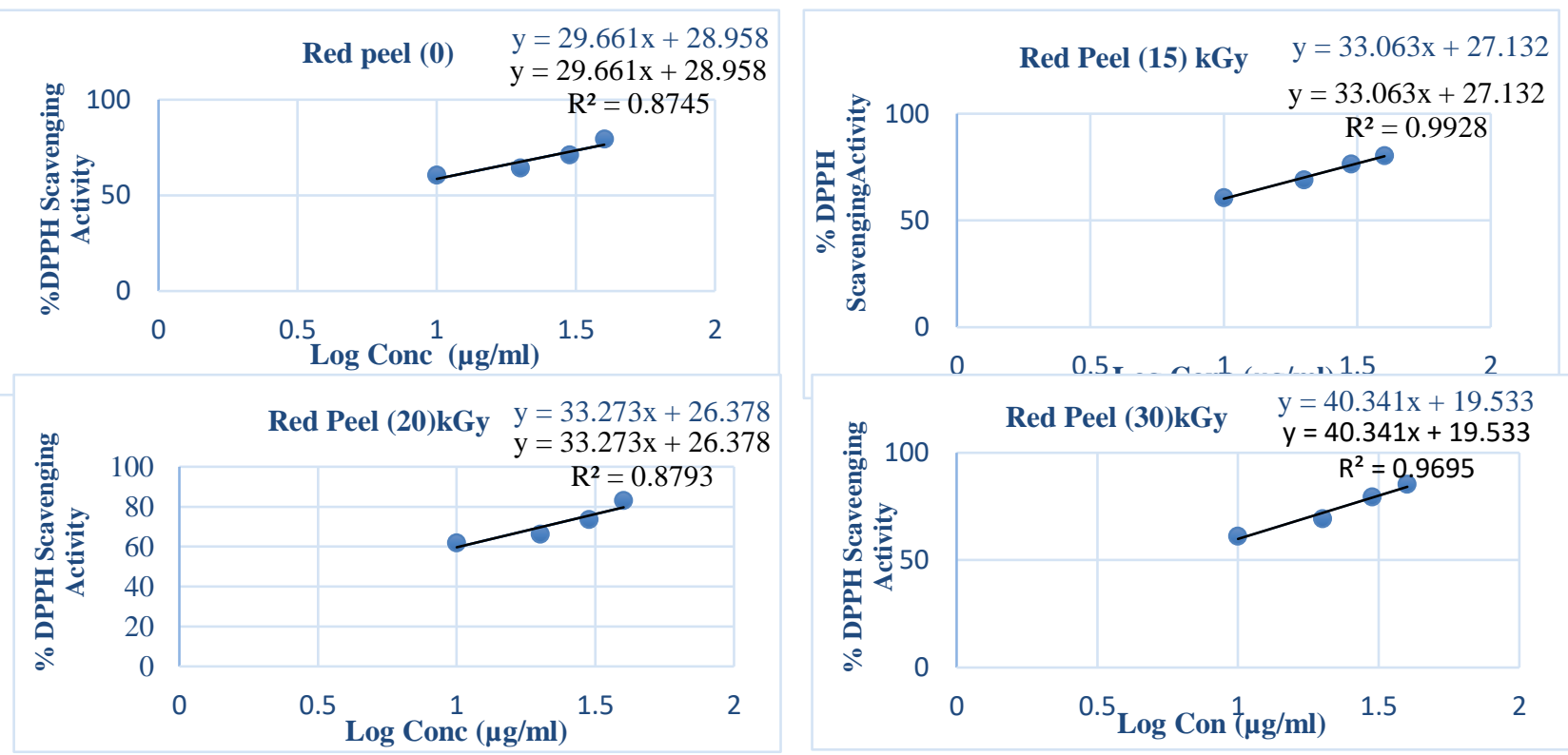

Fig. (1): Regression lines for determination of $\mathrm{IC}_{50}$ values of aqueous extracts of red peel of pomegranate 

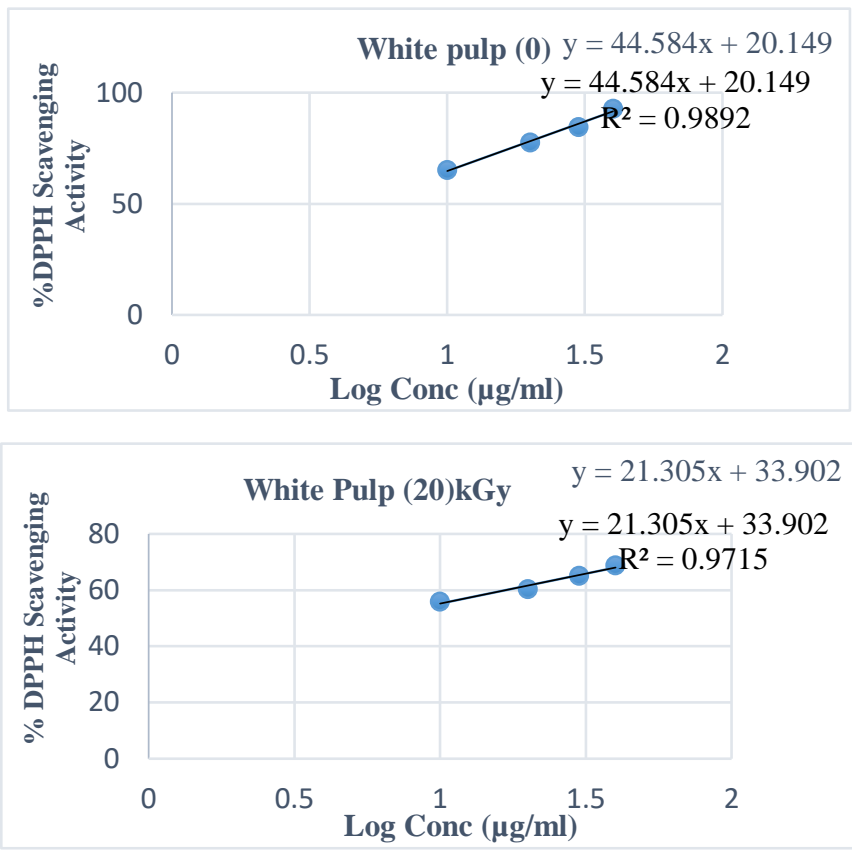
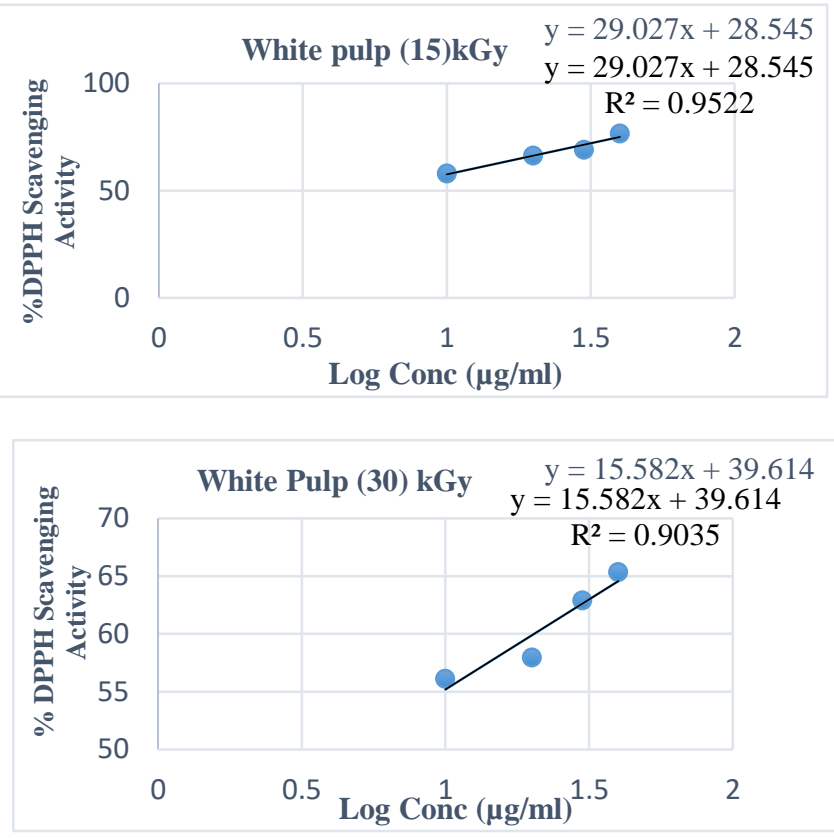

Fig.(2): Regression lines for determination of $\mathrm{IC}_{50}$ values of aqueous extracts of white pulp of pomegranate
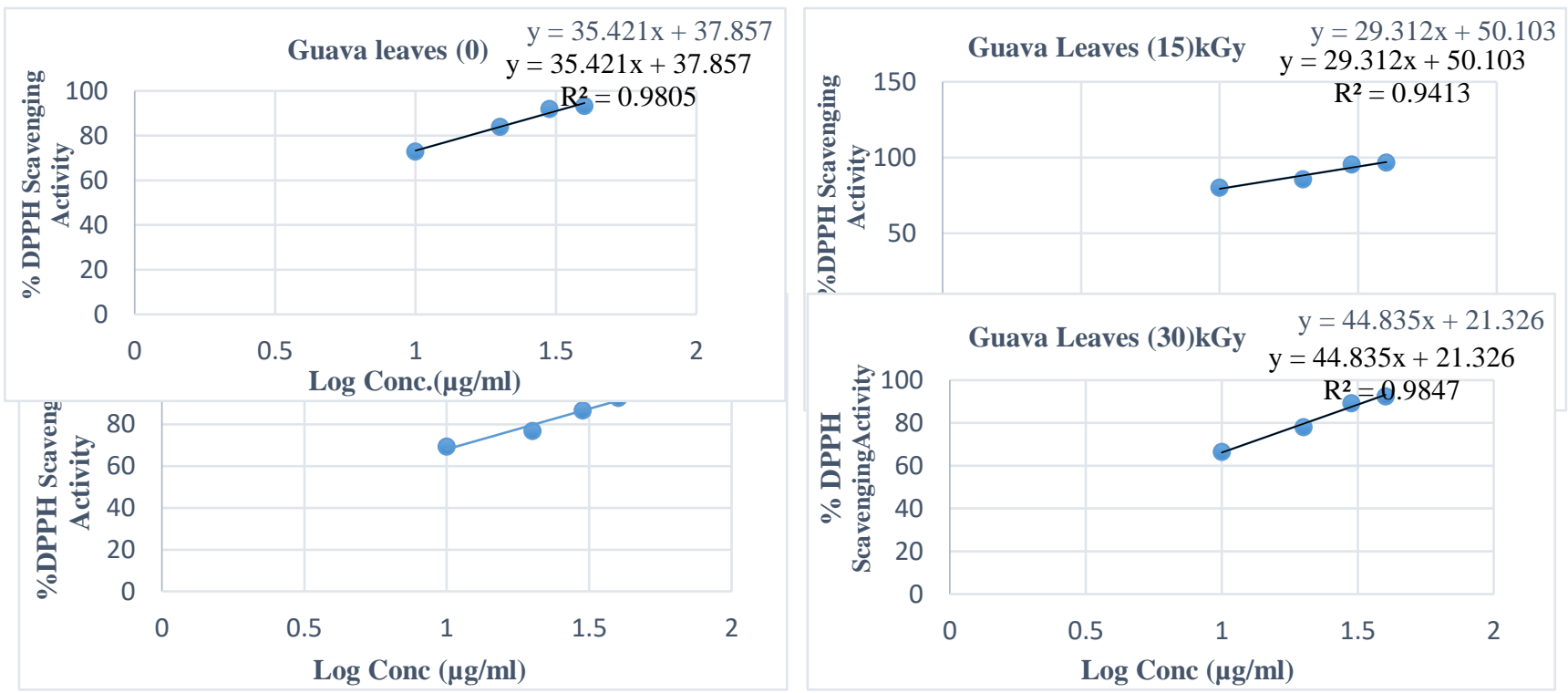

Fig.(3): Regression lines for determination of $\mathrm{IC}_{50}$ values of aqueous extracts of guava leaves 

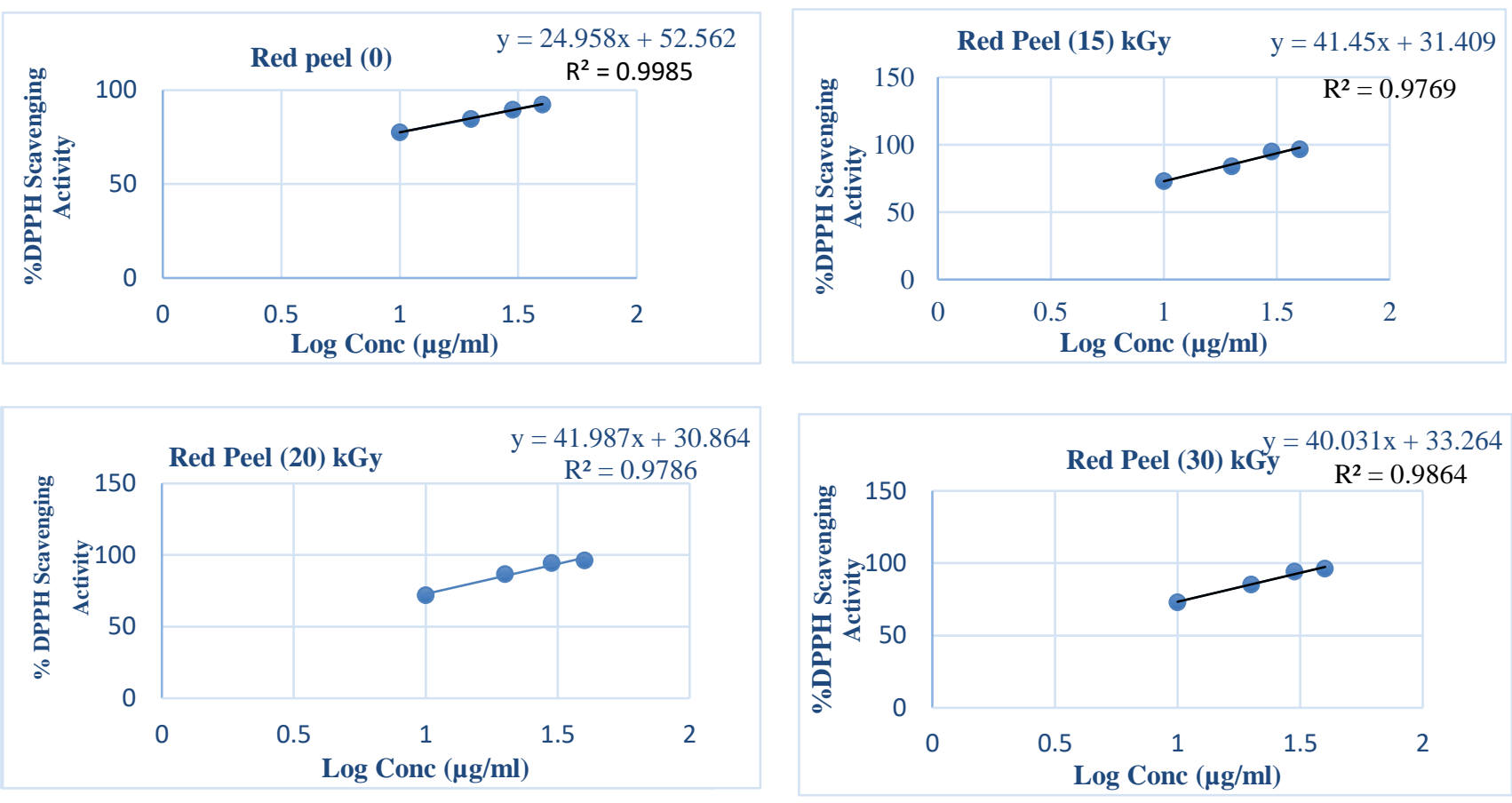

Fig.(4): Regression lines for determination of $\mathrm{IC}_{50}$ values of methanolic extracts of red peel of pomegranate
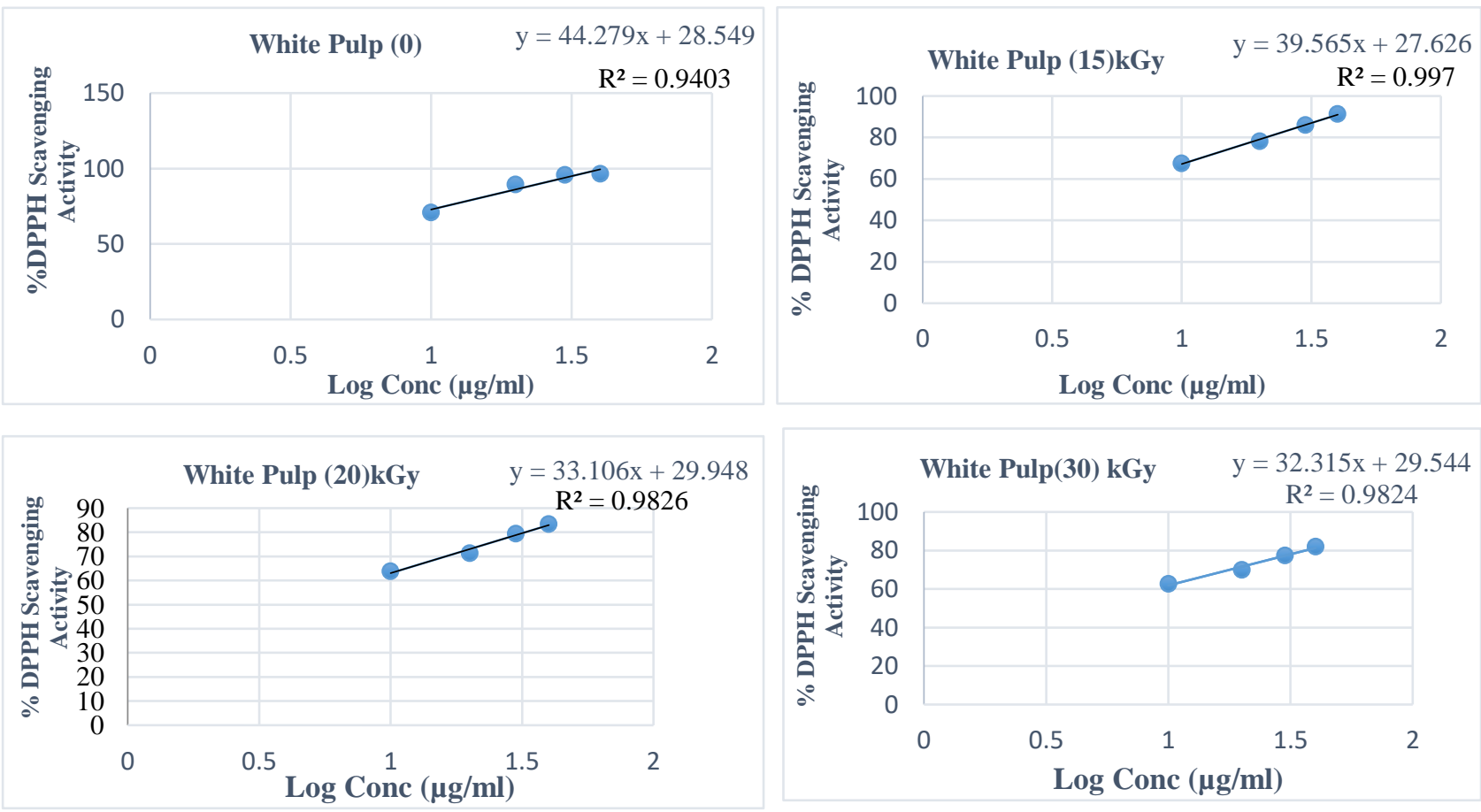

Fig. (5): Regression lines for determination of $\mathrm{IC}_{50}$ values of methanolic extracts of white pulp of pomegranate 

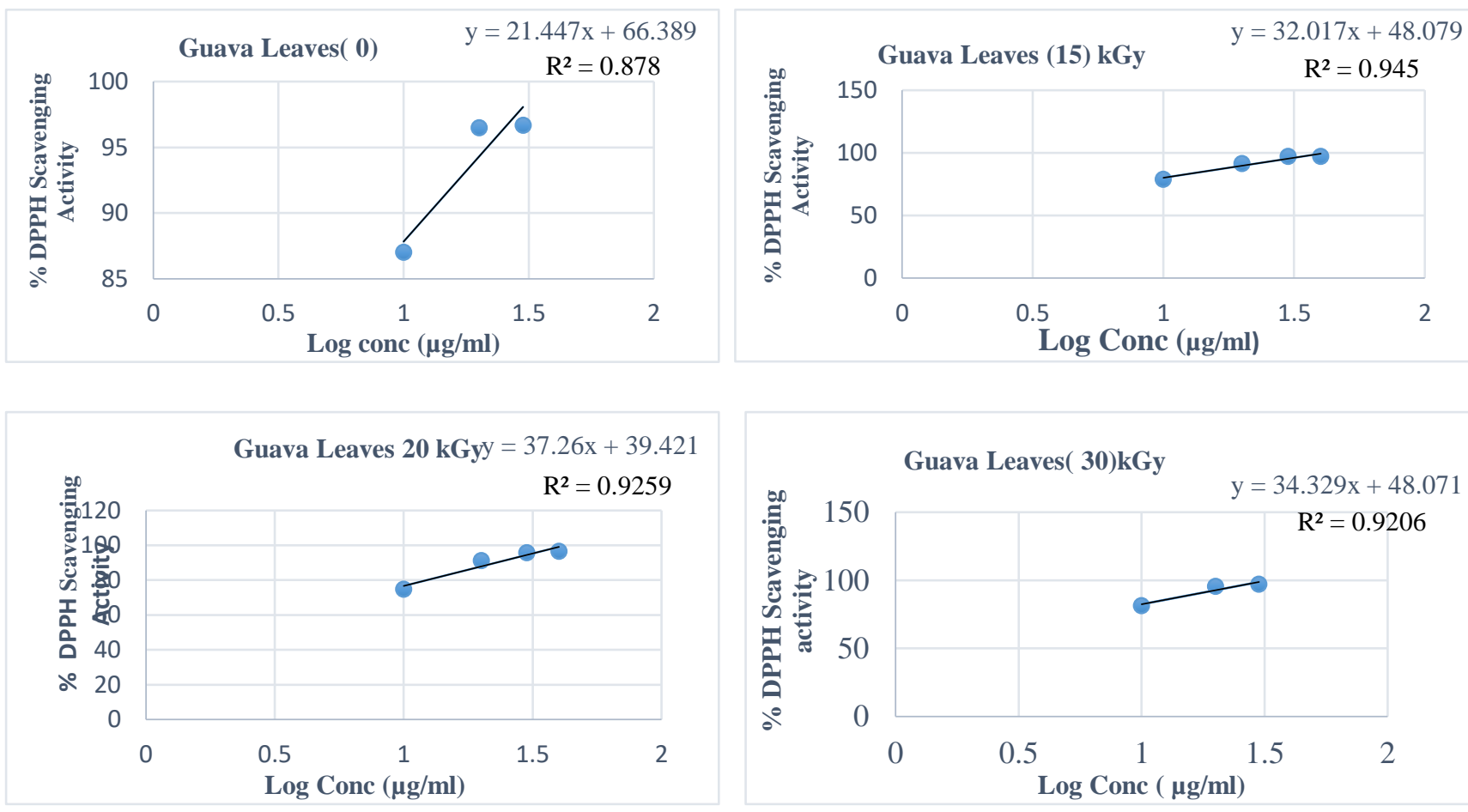

Fig. (6): Regression lines for determination of $\mathrm{IC}_{50}$ values of methanolic extracts of guava leaves

\section{References}

1. Liberty, J.T., Dickson, D.I., Achehe, A.E., J. of Multidisciplinary and Current Research,236-243(2013).

2. Morrison, R.m., Int. J. of Radiation on Applications and Instrumentation. Partc. Radiation Physics andchemistry,35,46,673-679(1990).

3. Mali, A.B., Kalpana Khedkar.,Smia S.Lele., Food and Nutrition Sciences, 2,428-433(2011).

4. Kebede,.C., Simachew, A., Disassa, H., et al., A.J. of Nutrition, 4,2, 77-83(2015).

5. Chodak,.A.D., Tarko,T., Acta Sci. Pol.,. Technol .Aliment. 6,3,29-36(2007).

6. Jalal, .H., Ashraf, M., Ahmed, S.R. et al .,The pharma Innovation Journal, 7,4,11271131(2018).

7. Sulieman, Abdel Moneim, E., Babiker, Wisal A.M., Elhardallou, S.B., et al., Int. J. of

Food

ScienceandNutritionEngineering,6,1,913((2016).
8. Mercy, S., Mubsira, S., Jenifer, I., Int. J. of scientific \& Technology Research,3,1,2277-8616(2014).

9. Saleh, E.A., Morshdy, A.M., Hafez, A.E., Hussein, M.A. et al., J. of Microbiology, BiotechnologyandFoodSciences, 6,6,13001304(2017).

10. Jaisinghani, R.N., Makhwana, S., Kanojia, A., Microbiology Research, 9,7480, DOI https://doi.org/10.4081/mr.2018.7480 (2018).

11. Sharifiyan, F., Attar, A.M., Nili, N. and Asgary, S., Adv.Biomed Res, 5-8(2016).

12. Asadi, M.S., Mir ghazanfari,S.M., Dadpay,M.,Nassireslami,E., Journal of Research in Medical andDentalScience,6,3,230-336(2018).

13. Díaz-de-

Cerio,E.,Verardo,V.,Caravaca,A.M.G.,Inte rnationalJ.Molecular Sciences, 18,897(2017).

14. Laily, N., Kusumaningtyyas, R.W., Sukarti, I., and Rini, M.R.D.K., Procedia chemistry, 14, 301-306(2015).

15. David, M., Abraham,T.J., Nagesh,T.S., J. AppliedAquaculture,29,3-4(2017).

Arab J. Nucl. Sci. \& Applic. Vol.53, No.3 (2020) 
16. Elsayed, M.R., Doaa, I., Elsayed, B.M., Bena Veterinary Medical Journal, 25,2, 2332(2013).

17. Anbuselvi,S. and Rebecca,J., J.Pharmaceutical Science and Research,9,12,2431-2433(2017).

18. Joseph, B., Priya, M., Int. J. of Pharma and Bioscience, 2, 0975-6299 (2011).

19. Ranvindranath, D., Nayara, O.V., Thomas, L., In Pharmaceutical Industry Biotechnology Research,2,11-14(2016).

20. Giri,S.S.,Sems.S., Cri, C., Kim, W.J., Park, S.C., Sukumaran,V., Fish shellfish Immunol., 46,217-224(2015).

21. Fawole, F.J., et al., Aquac. Res, 47,37883799(2016).

22. Gobi, N., et al., Fish Shellfish Immunol.,58,572-583(2016).

23. Mondal, A., Research Journal of Recent Sciences, 5,8,51-55(2016).

24. Islam, T., Afrin , N., Parvin, S., Dana, N., International Food Research Journal, 25,5,2062(2018).

25. Raja, S., J. of Chemical and Pharmaceutical Research,4,6,3239-3244(2012).

26. Ojedokum,A.T., Bello, O.S., Appl. Water sci,7,1965-1977(2017).

27. Yasoubi, P., Barzegar, M., Sahari, M.A.and Aziz, M.H., J. of Agricultural science and technology,9,35-42(2007).

28. A.O.A.C.,Official Methods of Analysis of the Association of Official Analytical Chemists .14th (Edn) .Washington, DC (1984).

29. Su, MS., Chien, PJ., Food Chemistry, 104,182-187(2007).

30. Polovka,M., Suhaj,M., J. Food and Nutrition Research, 52,45-60(2013).

31. Manasathien ,J. et al., G.J. Pharmacology, 6,131-141(2012).

32. Li,Y. et al., Food Chemistry,96, 254260(2006).

33. Elfalleh,W. et al., J. Medicinal plants Research, 6, 4724-4730(2012).

34. Viuda-Martosin, M. et al., Journal of Food Processing and Preservation 37,5,772776(2013).

35. Dadwal,V. et al., Int. J. Food and Nutritional Science,4,98-104(2017).

36. Mekni,M. et al.,Int. J. Curr. Microbiol. App. Sci ,7,1663-1682(2018).
37. Bassiri-Jahromi,S. and Doostkam,A., AIMS Agriculture and food,4,41-55(2019).

38. Kushwaha,S.C. et al., J. Environmental Science, Toxicology and Food Technology, 7,38-42(2013).

39. Shiban, M. S., Food and Nutrition Science, 3, 991-996(2012).

40. Mahmoud, K.A. and Ibrahim, G.E., J. Rad. Res. Appl. Sci,6,353-368(2013).

41. Abeed AL. Mashkor ,I,M.,Int. J. of Chem Tech Research,6,4656-4661 (2014).

42. Jeevarathinam,A. and Muthulakshmi,P.,Int.J. Pharmacy \& Pharmaceutical Research ,8(3),232241(2017).

43. Mehrizi, R.Z. et al., Journal of Food Quality and Hazards Control,4, 103-108(2017).

44. Guo,Ch.,Yang,J. et al., Nutrition Research,23,1719-1726(2003).

45. Kaur,Ch. and Kapoor,H,C., Int. J. Food Science and Technology,37,153161(2002).

46. Okonogi,S., Duangrat, C. et al., Food Chemistry,103,839-846(2007).

47. Kanatt,S.R., Chander,R. and Sharma, A.,Int. J. Food Science and Technology,45,216-222(2010).

48. Rajan, S., Mahalakshmi,S. et al., Int. J. Pharmacy and Pharmaceutical Sciences,3,82-88(2011).

49. Barathikannan, K. et al., BMC Complementary and Alternative Medicine,16-26(2016).

50. Dadwal,V. et al., Int. J. Food and Nutritional Science,4,98-104(2017).

51. Pal, J. et al., Biochemical and Cellular Archives, 17, 183-187(2017).

52. Pyrzynska, K. and Pekal, A, Anal.Methods,5,4288-4295(2013).

53. Ambigaipalan, P. et al., J. Agric. Food Chem,64, 6584-6604(2016).

54. Khatib, M. et al., International Journal of Food Sciences and Nutrition,4, 1-7(2017).

55. Vázquez -Araújo, L. et al.,Food Science and Technology , 44, 2119-2125 (2011).

56. Vázquez -Araújo, L. et al., Beverages, 1, 1733(2015).

57. Qian,H. and Nihorimbere,V., J Zhejiang Univ SCI 5,676-683(2004).

58. Chen,H.Y. and Yen,G.CH., Food Chemistry,101,686-694(2007). 
59. Vyas, N. et al., International Journal of Pharm Tech Research,2,417-419(2010)

60. Venkatachalam, R. et al., Free Radicals and Antioxidants, 2, 31-36(2012).

61. Mailoa, M.N. et al., In.J. Scientific \& Technology Research,3,236-241(2014).

62. Lamjud,K. et al., Acta Hort, 367372(2014).

63. Irondi, E.A.et al., J. Intercultural Ethnopharmacology,5,122-130(2016).

64. Akila B. et al., J. Pharmacognosy and Phytochemistry, 7, 3036-3039(2018).

65. Das, M. et al., Int. J. Health Sciences \& Research,9,39-45(2019).

66. Bhat, R., K. R. Sridhar and K. TomitaYokotani, Food Chemistry, 103,3,860866(2007).

67. Gumus, T. et al., Int. J. Food Properties, 14,830-839(2011).

68. Variyar, Prasad S. et al., International Journal of Food Science and Technology,33,533-537(1998).

69. Gustavo H. F. S. et al., Int. Nuclear Atlantic Conference; Recife, PE(Brazil) ,2429(2013).

70. El-Niely, H. F.G., Radiation Physics and Chemistry,76,1050-1057(2006).

71. Hamza, R. G. et al., Biochemistry\& Anal. Biochemistry,1,6, 1-6(2012).
72. Amro B. H. et al.,Sudanese Journal of Agricultural Sciences ,1, 111-117(2014

73. Chamani, M. et al., Int. J. Biology,Pharmacy and Allied Sciences (IJBPAS),3,9,2176-2187(2014).

74. Zarei, M. and Shawrang, P., J. Agricultural Sciences, 61,4,343-357(2016).

75. Janiak,M,A. et al., Natural Product Communications,12,2,181-184(2017).

76. Štajner, D. et al., Int. J. Mol. Sci, 8, 618627(2007).

77. De Camargo AC. et al., Journal of Functional Foods, 12,129-143(2015).

78. Pereira, C. et al., Innovative Food Science \& Emerging Technologies,26, 271277(2014)

79. Sallam,E.M. and Anwar, M.M., Int. J. Agriculture\& Biology, 19,48-52(2017).

80. Wang,Z. et al., the open Food Science Journal,5,17-25(2011).

81. Malviya, SH. et al., J. Food Sci Technol,51,12,4132-4137(2014).

82. Perez-Jimenez, J. and Saura-Calixto, F., Food Res. Int,39,791-800(2006).

83. Perez-Jimenez, J. et al., Food Res. Int,41,274-285,(2008).

84. Grazul, M. and Budzisz, E., Coord. Chem. Rev, 253,2588-2598(2009).

85. Sultana, B. et al., Molecules,14,6, 2167 2180(2009). 